\section{IJ§ER}

ISSN: 2149-5939
International Journal of Social Sciences and Education Research

Online, http://dergipark.gov.tr/ijsser

Volume: 1(1), 2015

\title{
Türkçe haber siteleri tasarımları ve görsel kullanımı ${ }^{1}$
}

\author{
Website designs and visual applications of Turkish news sites
}

\author{
Ali Emre Dingil2
}

\begin{abstract}
$\ddot{O} z$
Received Date: $01 / 01 / 2015$

Accepted Date: 01 / 02 / 2015

Bu çalışmada; Türkçe haber sitesi tasarımları ve görsel kullanımları incelenmiştir. Öncelikli olarak geçmişten günümüze haber sitelerinin gelişimi giriş bölümünde verilmektedir. Günümüzde haber sitesi tasarımlarının nasıl olduğu çizimlerle gösterilmektedir. Araştırmanın yöntemi olarak içerik analizi kullanılmıştır. Bu yöntem ile örneklem alınan haber siteleri taranmıştır. Bu araştırmada haber sitelerinin görsel kullanım ve siklığının ne olduğu, haberlerde gerçek (olay anı) ve arşiv fotoğraf kullanımının oranı, haber sitelerinde habere ait görsellerin haber içeriği ile uyumunun nasıl olduğu, haber konularına göre görsel eleman kullanımının dağılımın nasıl olduğu verilmektedir. Sonuç olarak bu araştırmada haber sitelerindeki görsel kullanımın nasıl olduğu ortaya konulmaktadır. Günümüzde Türkçe haber siteleri Amerika ve Avrupa'daki örneklerine göre fotoğraf kullanımı yaygındır. Görsellik, haberi anlatmadaki önemi haber sitelerine de yansimaktadir.
\end{abstract}

Anahtar Sözcükler: Görsel tasarım, online habercilik, haber sitesi tasarımı.

\begin{abstract}
Website designs and visual applications of Turkish news sites are analyzed in this study. The introduction deals with the development of news sites from past to present. Charts in this study show today's website designs of the news sites in Turkey. This study uses content analysis as a research method. News sites were scanned by using this method. This study also gives significant information on the use of visuals and its frequency, the proportion of actual and archive photography use in news, the harmony between the visuals and news content in news sites and personnel distribution regarding news topics. As a result, this study shows how visual applications look in Turkish news sites. Photography use is more common in Turkish news sites when compared to their American or European counterparts. Visual quality reflects its importance on the news sites.
\end{abstract}

Keywords: Visual design, online journalism, news site design.

\section{Giriş}

Teknoloji araçlarındaki hızlı değişim iletişim alanında da kendini göstermiş geleneksel medya (gazete, radyo, televizyon) yerine alternatif olarak yeni medya tabiriyle online gazetecilik ortaya çıkmıştır. Türkiye'de 1995 yılından gazeteler online yayıncılığa geçmektedir. Ülkemizde içeriğini internete aktaran ilk kuruluş olan Aktüel dergisidir ve 19 Temmuz 1995 tarihinde internet üzerinden yayın yapmıştır. Ardından aynı yıl Ekim ayında Leman Dergisi internete açılmıştır (Çakır, 2007: 138). Yayını internet ortamına aktaran ilk gazete Zaman Gazetesi, 1996'da Milliyet Gazetesi olmuştur (Çakır, 2007: 138).

Gelişen bilim, teknoloji ve özelliklede iletişim teknolojisi ile insanlar kitle iletişim araçları ile sarılmış durumdadır. Günlük hayatta gazete, radyo, televizyon, internette ve akıllı telefonları ile

\footnotetext{
${ }^{1}$ Anadolu Üniversitesi Sosyal Bilimler Enstitüsü “Türkiye'de Haber Sitelerinin Görsel-Tasarım Düzeyleri ve Etkinliği” isimli Yüksek Lisans tezinden üretilmiştir. (2014) Tez Danışmanı: Doç. Dr. Sibel Onursoy

${ }^{2}$ Research Assistant., University of Adnan Menderes, AYDIN/TURKEY, emredingil@gmail.com
} 
Dingil, A.E. (2015). Website designs and visual applications of Turkish news sites. International Journal of Social Sciences and Education Research, 1 (1), 250-261.

devamlı bir enformasyon alanı içindedirler. Akıllı cep telefonları ile çoğu kişi internete cep telefonlarından her an bağlanabilmektedir. Türkiye'deki online web sitelerine bakıldığında, ilk planda tasarımları birbirine benzese de detaylı incelendiğinde farklı kullanımlar göze çarpar. Bu bağlamda online haber siteleri de kendilerine farklı tasarımlar ve farklı görsellerle okuyucuları çekme yarışı içindedir.

Devlet Planlama Teşkilatı'nın verilerine göre (2011:13) Türkiye'de bilgisayar ve internet kullanımı hızla artmaktadır. Türkiye İstatistik Kurumu'nun 2013 yılı Nisan ayında gerçekleştirilen Hanehalkı Bilişim Teknolojileri Kullanım Araştırması sonuçlarına göre Türkiye genelinde hanelerin \%49,1'i evden İnternete erişim imkânına sahiptir. Türkiye İstatistik Kurumu'nca 2013 y1lında yapılan araştırmaya göre, internet kullanan bireyler, interneti en çok \%75.6 ile online haber, gazete ve dergi okumak için kullanmaktadır. Bu yüzden haber siteleri tasarımı önem taşımaktadır. $\mathrm{Bu}$ araştırmada "Online haber siteleri tasarımlarının ve görsellerinin nasıl yer aldığı" araştırmanın problemini oluşturmaktadır.

\section{Amac}

Haber siteleri tasarımlarının ve görsellerinin nasıl yer aldığı bu araştırmanın genel amacını oluşturmaktadır. Bu doğrultuda online haber sitelerinin görsel boyutu araştırılarak, tasarım özelliklerinin neler olduğu belirlenecektir. Bu amaç doğrultusunda Türkiye'deki haber sitelerinin ana sayfaları incelenerek alt amaç sorularına yanıt aranacaktır:

- Haber sitelerinde görsel kullanım şekli ve sıklığı nedir?

- Haberlerde gerçek görsel kullanım durumu nedir?

- Haber sitesinde habere ait görsellerin haber içeriği ile uyumu nasıldır?

- Haber bağlantıları ve görsel eleman kullanımında, tasarım ne şekilde uygulanmaktadır?

- Haber konularına göre görsel kullanımı dağılımı nasıldır?

Online gazetecilik, gazetecilik mesleğinin haber toplama pratikleri kullanılarak, insanların internet aracılığıyla bilgilendirilmesi şeklinde tanımlanabilir. Online yayınlar, bir menüye dayand1rilan formatta daha geniş türde haber seçeneği sunar. Online servisler genellikle geleneksel gazetelerin derinliklerine gömülen bilgilere kolay erişme imkanı sağlar (Tewksbury ve Althaus, 2000: 457) İçinde yaşadığımız dijital çağ, diğer birçok alanda olduğu gibi kitle iletişim araçlarını da yap1 ve yöntem bakımından değişime zorlamaktadır. Gazeteler varoluş nedenleri olan haber verme işlevlerini, geleneksel yapısının yanı sıra internet ortamında da sürdürmeye çalışan etkin bir medya ortamıdır. Haber, "toplumun bilgi ve ilgisini geliştirecek, dönüştürecek, gerçekliğin, kurgusal olarak yayımlanacak medya organizasyonunun yapısına, teknolojisine ve ideolojisine göre yeniden kurgulanmasıdır. Haber içinde barındırdığı çok katmanlı yapısı nedeniyle formel olarak düzenlenişi, tanımlanmasından ve kavramsallaştırılmasından daha kolay bir iletişimsel yapılanmadır" (Rigel, 2000: 65). Bu yapılanmanın internet ortamında yayınlanmasına online, sanal, dijital, elektronik gazetecilik, ayrıca web ya da internet gazeteciliği de denilmektedir. Online gazetecilik ayrıca gazeteciliğin çeşitli yöntemlerinin kullanılarak insanların internet aracılığıyla bilgilendirilmesi" şeklinde tanımlanabilir. İnternet gazeteleri, internet ile özellikle 1994'ten sonra gelişen ve dünya çapında yaygınlaşan bir iletişim aracıdır (Yüksel-Gürcan, 2001:18). 
Dingil, A.E. (2015). Türkçe haber siteleri tasarımları ve görsel kullanımı. International Journal of Social Sciences and Education Research, 1 (1), 250-261.

Ülkemizde de 1995 yılından itibaren gazeteler içeriklerini online olarak yayınlamaya başlamışlardır. Ülkemizde içeriğini internete aktaran ilk kuruluş olan Aktüel Dergisi'dir ve 19 Temmuz 1995 tarihinde internet üzerinden yayın yapmıştır. Ardından aynı yıl Ekim ayında Leman Dergisi internete açılmıştır (Çakır, 2007: 138). Yayını internet ortamına aktaran ilk gazete Zaman gazetesidir. Zaman gazetesi 2 Aralık 1995 tarihinde haber ve köse yazıları baslıklarını internet üzerinden vermeye başlamıştır. Milliyet gazetesi 27 Kasım 1996'da gazetenin tamamını internete aktaran ilk gazete olmuştur. Hürriyet ve Sabah gazeteleri ise 1 Ocak 1997 tarihinden itibaren internet ortamına geçmişlerdir (Çakır, 2007:138). İlk internet gazetesi ise XN'dir (Karaduman 2005: 145-146). Kendi haberlerini üreten ilk haber sitesi ise 1998 yılında yayına başlayan Net Gazete'dir (Çevikel,2004:147-165).

İçeriği tamamen kendine özgü olan ve bağımsız yayıncılık yapan ilk site, gazeteci Ahmet Tezcan'ın kurduğu www.dorduncukuvvetmedya.com'dur. Televizyonda program olarak yayınlanan "Dördüncü Kuvvet Medya" bu olanağını kaybedince, İnternete taşınarak medya etiği konusunda duyarlı gazetecileri de aynı ortamda buluşturmuştur. Mayıs 1998'de İnternet üzerinden yayınlanmaya başlayan site, hiçbir gruba bağlı olmadan yayın yapan sitelerin de öncülüğünü yapmıştır. 2000 yılının başında ise büyük sermaye gruplarına bağlı olmayan gazetecilerin öncülüğünde birçok haber sitesi yayına geçmiştir. Bunda medyada yaşanan ekonomik krizin etkisi de büyüktür. Birçok deneyimli gazeteci işsiz kalmış ve mesleklerini İnternette açtıkları sitelerle sürdürmüşlerdir. Bu durum, Türkiye'de İnternet gazeteciliğinin gelişmesine olumlu katkı sağlamıştır (MEB, 2011:5).

Superonline'nin İnternet sitesinde haber yayınlaması benzer siteleri de aynı şekilde ziyaretçilerini son gelişmelerden haberdar etme zorunluluğuna itmiştir. Servis sağlayıcı firmalar İnternet sitelerinde haber yayınlamaya başlamışlardır. Şu anda ister amatör olsun ister profesyonel, İnternet sitelerinin büyük çoğunluğu son dakika haberlerine sitenin bir köşesinde yer ayırmaktadırlar. Böylece, önemli bir gelişme dakikalarla sınırlı bir zamanda milyonlarca kişiye kısa bir sürede ulaşabilmektedir (MEB, 2011:5).

Türkiye'de internet gazeteciliğinin gelişimi 1995-2000 ve 2000'den sonrası olarak iki dönem olarak ele alınabilir. İlk dönem, internetin yeni geliştiği dönemdir ve gazeteciler arasında yeni tanınmaktadır. Bu nedenle ilk dönemde haber siteleri gazetelerin sanal ortamdaki kopyaları durumundadır. Ancak ikinci dönemde, gerçek anlamda internet gazeteciliğinden bahsedilebilir. Bu dönemde yatırım gerektirmeyen haber siteleri özellikle işsiz kalan gazetecilerin yönelimiyle hızla artmıştır ve yalnızca internet üzerinden yayın yapan haber portalları devreye girmiştir (Çakır, 2007: 139). Bilişim teknolojileri kullanım araştırmaları sonuçlarına göre 2013 yılı sonuçlarına göre en yüksek oranı internet üzerinden sosyal gruplara katılma $(\% 73,2)$ ve online haber, gazete ve dergi okuma $(\% 75,6)$ amacı başı çekmektedir. Ardından e-posta gönderme ve alma $(\% 62,5)$, mal ve hizmetler hakkında bilgi alma $(\% 59,9)$ ve sağlıkla ilgili bilgi arama $(\% 59,6)$ gibi amaçlar önde gelmektedir (Tüik 2013).

ABD İnternet Kurulu'nun yayınladığı İnternet Raporu'nda da Türkiye İstatistik Teşkilatı verileriyle örtüşmektedir. İnternet Kurulunun yayınladığı internet raporunda internet kullanıcılarının en popüler 10 etkinliği arasında online haber okuma üçüncü sırada yer almaktadır. İlk sırada e-mail, ikinci sıra webde sörf, ardından alışveriş, eğlence, bankacılık işlemleri, hobi, sağlık ve seyahat amaçlı bilgi arama etkinliklerinin takip ettiği listede online haberciliğin payı dikkat çekicidir (Güler, 2007:156) 
Dingil, A.E. (2015). Website designs and visual applications of Turkish news sites. International Journal of Social Sciences and Education Research, 1 (1), 250-261.

\section{Online haber sitesi tasarımı}

Günümüzde yayınlanan ulusal boyutta haber sitesi tasarımında kayan fotoğraflar yaygın olarak kullanılmaktadır. Bu kullanım İngilizce olarak "slider" olarak bilinir. alexa.com'un verilerine göre Türkiye'de en çok tıklanan ilk altı haber sitesinde üç farklı çeşit kayan fotoğraf kullanımı vardır. Yatay kayan fotoğraflar, dikey kayan fotoğraflar, haber türüne göre seçmeli kayan fotoğraflardir.

Yatay kayan fotoğraflar: Soldan sağa doğru, sağdan da sola doğru kayan fotoğraflardan oluşmaktadır. Genellikle fotoğraf üzerinde haber başlığı yer almaktadır. Fotoğrafların altında ya da üstünde küçük tuşlarda ya fotoğraf ya da rakamlar bulunmaktadır. Rakamlar üzerinden istenilen habere geçilebilmektedir.

Şekil 1. Yatay kayan fotoğraflar

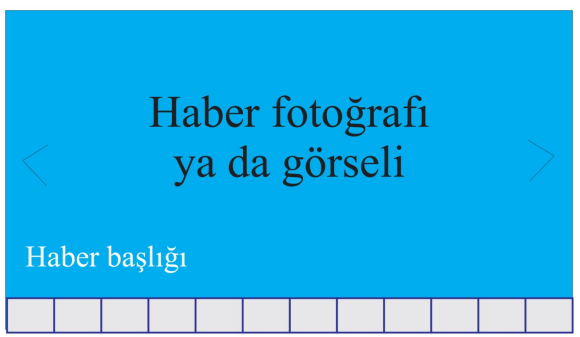

Şekil 2. Dikey kayan fotoğraflar

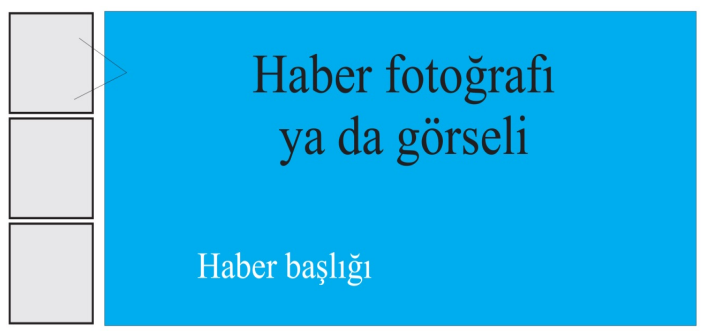

Dikey kayan fotoğraflar: Yukarıdan aşağı ya da aşağıdan yukarı kayan fotoğraflardan oluşmaktadır. Genellikle fotoğraf üzerinde haber başlığı yer almaktadır. Fotoğrafların solunda ya da sağında küçük tuşlarda ya fotoğraf ya da rakamlar bulunmaktadır. Tuşlardan istediğiniz habere geçilebilmektedir.

Haber türüne göre seçmeli kayan fotoğraflar: Görselin hem üstünde hem altında tuşlar bulunmaktadır. Üsteki tuşlarda genellikle haber türleri alttaki tuşlarda ise haberler yer almaktadır. Üsteki haber türünden hangisi seçilirse, alttaki tuşlardan haber, türüne göre değişir.

Şekil 3. Haber türüne göre seçmeli kayan fotoğraflar

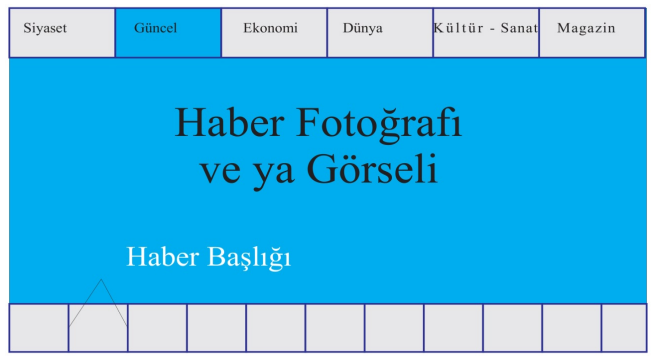

Amerika, İngiltere ve Almanya'da kayan görsel kullanımı Türk haber siteleri kadar yaygın değildir. alexa.com'un verilerine göre en çok kayan görsel kullanımı sıklığına sahip ve ana sayfasında manşet haberleri kayan görsel uygulamasıyla veren haber siteleri hurriyet.com.tr, milliyet.com.tr, haber7.com, haberturk.com, haberler.com ve sabah.com.tr'dir. Amerika'da en sık kullanılan (tıklanma olarak) haber siteleri, cnn.com, wordpress.com, foxnews.com; İngiltere'de bbc.co.uk, dailymail.co.uk, the guardian.com; Almanya'da spiegel.de, tonline.de ve focus.de'dir ve tasarımlarındaki uygulamalar farklıdır. Bu sitelerde genelde manşetler sitenin üst tarafında büyük bir haber fotoğrafı ile birlikte bu fotoğrafın üstünde ya da altına başlık ve haberin bir kısmı verilerek kullanılmaktadır. 
Dingil, A.E. (2015). Türkçe haber siteleri tasarımları ve görsel kullanımı. International Journal of Social Sciences and Education Research, 1 (1), 250-261.

Sık kullanma oranlarına sahip haber sitelerinin tasarımlarının da benzeştiği göze çarpmaktadır. $\mathrm{Bu}$ haber sitelerinin tasarım benzerlikleri göz önünde bulundurulduğunda dört tür haber sitesi tasarımı ortaya çıkmaktadır:

Birinci tür: Manşet haberleri yatay fotoğraflarla verilmektedir. Yatay bir görsel alanın üstünde sür manşet haberleri yer almaktadır. Sür manşet haberleri, fotoğraf ve başlık şeklinde sıralanmaktadır. Kayan görsellerin alt kısmında, görsel, başlık ve spot şeklinde haberler sıralanmaktadır. Haber sitesinde aşağı doğru inildikçe magazin, foto galeri, video galeri, spor haberleri yine kayan görsel uygulamaları olarak verilmektedir. Manşetteki kayan görsel uygulamanın yanında haber başlıkları bağlantı olarak verilmektedir.

Şekil 4. Birinci tür haber sitesi tasarımı

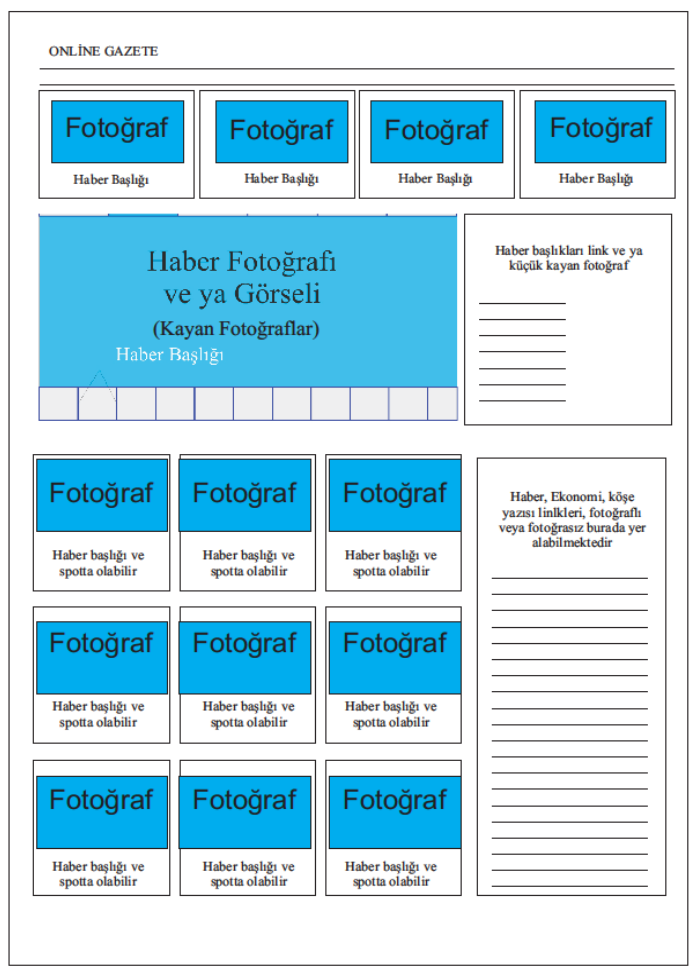

(hürriyet.com.tr, haber7.com haberturk.com, haberler.com gibi)
Şekil 5. İkinci tür haber sitesi tasarımı

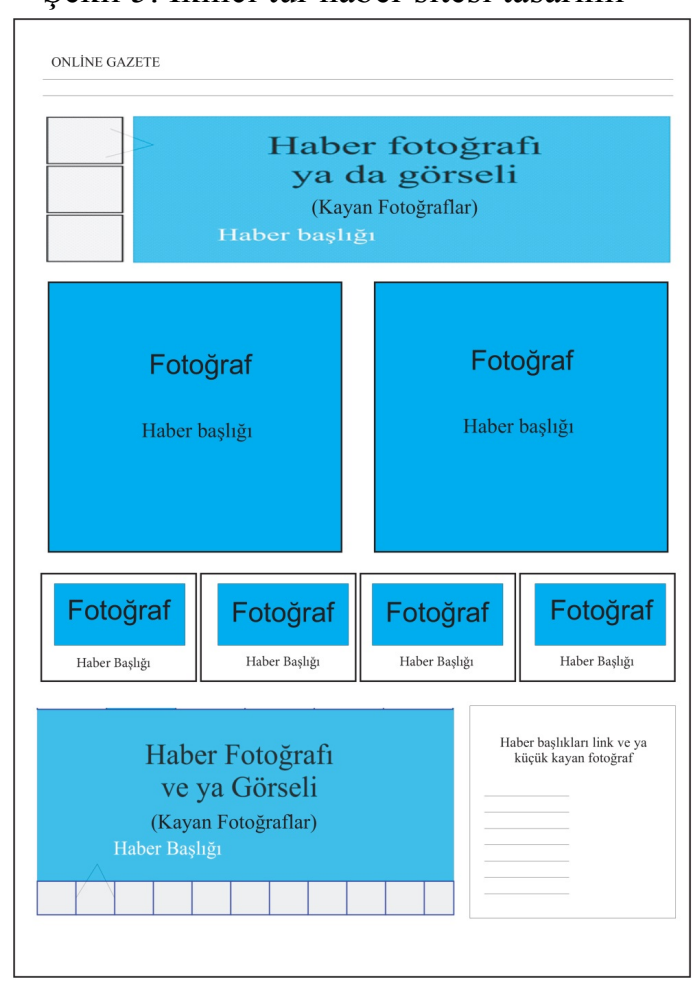

(milliyet.com.tr, sabah.com.tr gibi)

Íkinci tür: Ana sayfada en üstte sür manşet, dikey kayan pul fotoğraflar (bazı sitelerde tek fotoğraf) ve büyük bir görsel alanı, onun altında iki adet büyük fotoğraf alanı, görselle birlikte verilen haber başlığ 1 , onun altında şerit halinde küçük fotoğraf haber başlığı, onun altında da yatay kayan fotoğraflar şeklinde devam eden sayfa düzeni kullanılmaktadır.

Üçüncü tür: Bu tür haber sitelerinde kayan görsel uygulaması kullanılmamaktadır. Sitenin en üstünde büyük fotoğraf ile manşet haber yer almaktadır. Alta doğru daha küçük alanlarda diğer haberlere yer verilmektedir. Fotoğraf yanında ya da altında başlığı, spotu, haberin girişi bulunmaktadır. Sadece haberin başlığı verilerek bağlantılar aracılığıyla, okur habere yönlendirilmektedir. 
Dingil, A.E. (2015). Website designs and visual applications of Turkish news sites. International Journal of Social Sciences and Education Research, 1 (1), 250-261.

Şekil 6. Üçüncü tür haber sitesi tasarımı

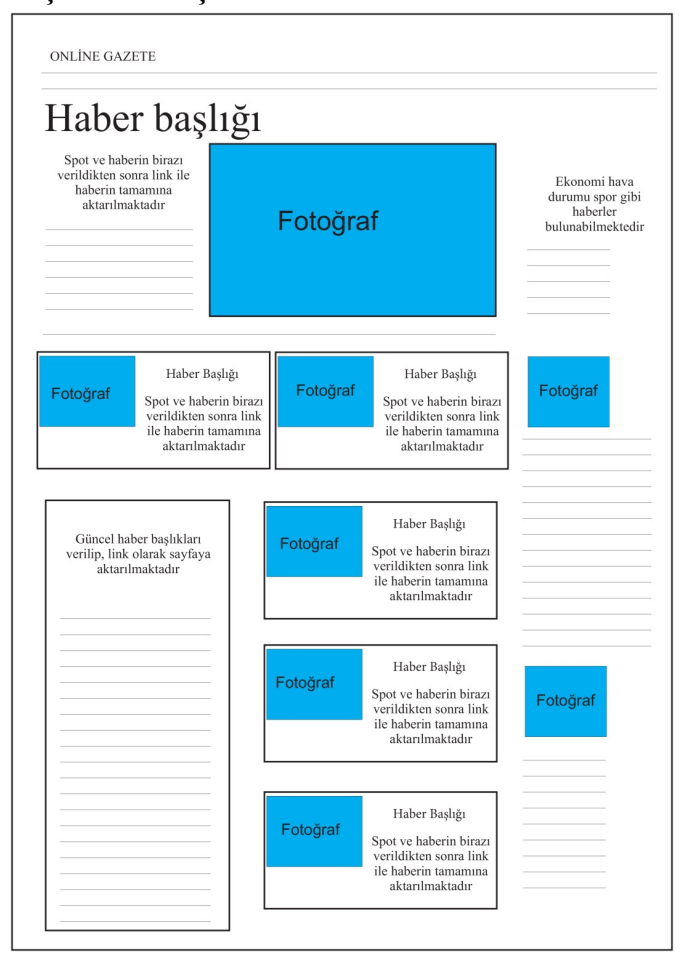

(Amerika'da yayınlanan
Şekil 7. Dördüncü tür haber sitesi tasarımı

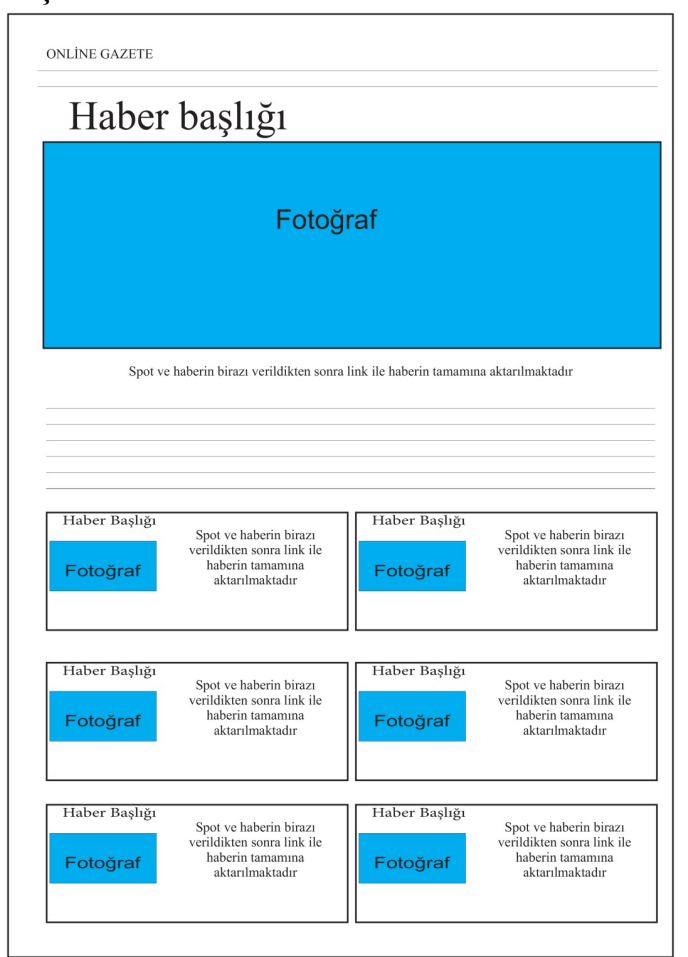

(İngiltere'den dailymail.com, Almaya'dan spigel.de ve focus.de gibi) ardien.com; Almanya'dan tonline.de gibi)

Dördüncü tür haber siteleri: Haber sitesinin en üstünde büyük bir fotoğraf ile manşet haberi verilir. Ana sayfada haberin fotoğrafı, başlığı spotu ya da haberin bir kısmı verilerek bağlantıyla habere yönlendirilmektedir. Alta doğru haberin önemlilik dercesine göre tek sütun ya da iki sütun şeklinde haberler sıralanmaktadır.

2000'li yıllara kadar multimedia yaygın değildi. Onursoy'un (2001:55- 60) çalışmasında online gazete tasarımlarını ters yatay ve dikey hatlar, L-şeklinde hatlar, çift taraflı hatlar, açık hatlar, görünmez hatlar, görünür hatlar, yatay hatlar ve dikey hatlar şeklinde ayırmaktadır.

Amerikalı araştırmacılar Garcia ve Stark 1998 yılında 90 haber sitesi kullanıcısı üzerinde bir araştırma yaparlar. Haber sitesi kullanıcılarının gerçekte okumadıklarını sayfa üzerinde göz gezdirdiklerini, göz taramasını bırakıp okumaya başladıkları noktaya "giriş noktası" adını vermişlerdir. Çalışmada genellikle giriş noktasının fotoğraf, sonrasında başlık ya da başka bir fotoğraf olduğunu gözlemlemişlerdir. Hansen, Copenhagen Det Fri Aktuelt Gazetesinin 12 haber sitesi kullanıcısıyla gerçekleştirdiği çalışmada da onların önce fotoğrafa sonra ikon ve grafiklere baktıklarını belirlemiştir.(Onursoy, Kılıç, Er, 2010: 79-80.)

Uçak'ın (2012:79) yaptığı araştırmada basılı gazetelerde fotoğraf kullanımı ile gazetelerin internet sayfalarında fotoğraf kullanımı arasında belirgin farklar görülür. İnternet sayfasında fotoğrafın öne çıkarıldı̆̆ı, yazının arka planda kaldığı bir tasarım görülmektedir.

\section{Yöntem}

$\mathrm{Bu}$ çalışmada içerik analizi yöntemi kullanılmaktadır. Türkçe yayınlanan ve sık kullanılan (tık alan) haber sitelerinden (alexa.com'un verilerine göre) ilk beş haber sitesi (www.hurriyet.com.tr, 
Dingil, A.E. (2015). Türkçe haber siteleri tasarımları ve görsel kullanımı. International Journal of Social Sciences and Education Research, 1 (1), 250-261.

www.milliyet.com.tr, www.haber7.com, www.haberturk.com.tr, www.haberler.com) ana sayfaları, 24 Şubat-2 Mart 2014 tarihleri arasında analiz edilmektedir. Haber sayıları, fotoğraflı haberler, gerçek ve eş zamanlı fotoğraf kullanımı, görsel ve haber uyumu, fotoğraf la birlikte haber başlığı kullanımı, foto galeri uygulamaları analiz edilmektedir.

\section{Bulgular ve yorum}

Haber sitelerinin görsel boyutu örneklem alınan 5 haber sitesi (www.hurriyet.com.tr, www.milliyet.com.tr, www.haber7.com, www.haberturk.com.tr, www.haberler.com.) 24 Şubat2 Mart 2014 tarihi arasındaki bir hafta boyunca analiz edilmiştir. Örneklemdeki haber siteleri ana sayfalarında fotoğraflı haber yer verilme oranı ortalama \%82'dir. Haber sitelerinde görsel elemanların kullanımının ön planda olduğu görülmektedir.

Görsel elemanlarla başlık, haber spotunun birlikte kullanılması oldukça yaygın bir uygulamadır. Örneklemdeki haber sitelerinde yazı ya da başlık, ortalama \%25 oranında görsel eleman üzerine bindirilmekte ya da $\% 75$ oranında görsel elemanın yanında birlikte verilmektedir.

Haber siteleri bazı haberleri -gerçek eş zamanlı- bazı haberleri ise kendi arşivlerinde yer alan fotoğrafları kullanmaktadır. Haberlerin -gerçek eş zamanlı- fotoğrafların kullanımı \%16'dır. Arşiv fotoğraf kullanımı ise $\% 84$ 'dür. Bu da göstermektedir ki haber siteleri stok fotoğraf kullanımina dayalıdir.

Haber sitelerinde yer alan haberlerde kullanılan görseller bazı haberlerde haber ile uyumsuz olabilmektedir. Örneklem alınan haber sitelerinde haber ile görsel uyum oranı \%89'dur. Haber sitelerinde bazı haberler fotoğraf galeri ya da video şeklinde verilmektedir. Örneklem alınan haber sitelerinde ana sayfada yer alan haberlerin \% 11 'i fotoğraf galerilerine yönlendirmektedir. \%14 ise video galerilerine yönlendirmektedir.

Haber sitelerinde bazı fotoğraflarda kadın figürü, cinsellik veya şiddet unsuru içeren fotoğraflar yer almaktadır. Araştırmada çıkan verilere göre en çok tıklanan haber sitelerinin ana sayfasında kadın figürü kullanımı \%19'dur. Cinsellik ise \%8 oranında kullanılmaktadır Şiddet fotoğrafı kullanımı ise \%1'i bile bulmamaktadır.

Haber siteleri ana sayfalarında birçok haber türü yer almaktadır. Bu haberlerin fotoğrafları da kendi haber konusuna ait fotoğraflara yer vermektedir. Araştırmada siyaset, polis-adliye, magazin, sağlık, spor, ekonomi, köşe yazısı türlerine ait haberlerin fotoğrafları, haber siteleri ana sayfasında taranmıştır.

Tablo 1. Haber siteleri ana sayfasında yer alan fotoğraflarda haber konuları sıklığı

\begin{tabular}{|l|c|c|c|c|c|}
\hline & Hürriyet & Milliyet & Haber 7 & Habertürk & Haberler \\
\hline Siyaset fotoğrafı & $\% 9,3$ & $\% 6,8$ & $\% 18,4$ & $\% 5,5$ & $\% 17,7$ \\
\hline Polis Adliye Fotoğrafı görseli say1s1 & $\% 2,9$ & $\% 4,7$ & $\% 2,4$ & $\% 5,2$ & $\% 11,7$ \\
\hline Magazin görseli & $\% 34,5$ & $\% 37,5$ & $\% 1$ & $\% 27,2$ & $\% 19,9$ \\
\hline Sağlık görseli sayısı & $\% 6,7$ & $\% 10$ & $\% 4,3$ & $\% 6,6$ & $\% 5,4$ \\
\hline Spor fotoğrafı & $\% 8,6$ & $\% 10,1$ & $\% 4$ & $\% 10,2$ & $\% 14,7$ \\
\hline Ekonomi fotoğrafı sayıs1 & $\% 4$ & $\% 5$ & $\% 5,1$ & $\% 7,2$ & $\% 8,2$ \\
\hline Köşe yazısı fotoğrafı sayısı & $\% 0$ & $\% 13$ & $\% 3,4$ & $\% 6,8$ & $\% 0$ \\
\hline
\end{tabular}


Dingil, A.E. (2015). Website designs and visual applications of Turkish news sites. International Journal of

Social Sciences and Education Research, 1 (1), 250-261.

Tablo 1'de görüldüğü gibi çıkan sonuçlara göre magazin konulu fotoğraflar ana sayfada daha çok yer almaktadır. Ardından siyaset haberleri ve spor haberleri gelmektedir. En çok tıklanan haber sitelerinde her türden habere yer verilmektedir.

Günümüzde Türkiye'deki haber siteleri, kayan resimleri (slider), yaygın olarak kullanmaktadır. Kayan resimlerde her türlü haber konusuna yer verilmektedir. Kayan resimlerde foto galeri ve video galeri de bulunmaktadır.

Araştırmada en çok tıklanan haber sitelerinin ana sayfasında 1'den 17'ye kadar slider kullanım1 mevcuttur. haberturk.com 1, milliyet.com 4, haberler.com 6, hurriyet.com 13 ve haber7.com 17 slider kullanmıştır. Bu kullanılan slider haber sayısı 3'den başlayıp 20'ye kadar çıkmaktadır. Haber sitelerinde kullanılan sliderlar genellikle haber sitelerinin en üstünde yer almaktadır. Bazı sitelerde sürmanşet sliderı üç haber içeren şeklinde kullanılmaktadır. Onun altında ise manşet haberlerinin yer aldığı yatay 10 ile 20 arası haber bulunan ve her türlü haber konusunu içeren haberlerin olduğu slider bulunabilmektedir.

İçerik analizi araştırmada haber sitesinin ana sayfalarında yer alan görselleri inceledikten sonra genel tarama modeli yöntemi ile haber sitesi kullanıcısı tutumu incelenmiştir.

\section{Sonuç}

İçerik analizi ile elde edilen verilere göre Türkiye'de en çok tıklanan haber sitesinin hepsinde kayan fotoğraflar (slider) bulunmaktadır. Haber sitelerin ana sayfasından çoğunlukla fotoğraf kullanımı hakimdir. Buna göre giriş bölümünde "online haber siteleri tasarımları" başlığı altında yer alan kayan fotoğraflı 1 . ve 2 . Tür haber sitesi tasarımlarına uyan uygulamalardır.

İçerik analiz yönteminde Türkçe yayınlanan haber sitelerinde en çok tıklanan ilk beş haber sitesi (www.hurriyet.com.tr, www.milliyet.com.tr, www.haber7.com, www.haberturk.com.tr, www.haberler.com.) içerik analiz yöntemi ile taranmıştır.

$\mathrm{Bu}$ tarama da elde edilen verilere göre taranan haber sitelerinin ana sayfaları görsel ağırlıklıdır. Taranan haber sitelerinin ana sayfalarında 100 adet üzeri haber yer almaktadır. Bu haberlerin $\% 70$ ile \%97 arasındaki haber fotoğraflı olarak verilmektedir. Bu fotoğrafların bazıların üzerinde başlık ve spot bulunmaktadır. Üzerinde başlık ve spot bulundurma oranı \%14 ile \%50 arasında sıklığa sahiptir. Diğer haberlerin başlığı ve spotu haberin altında ya da yanında yer almaktadır. Haber sitelerinde 3/4'den fazla arşiv fotoğrafı kullanmaktadır. Gerçek fotoğraf kullanım oranı düşüktür. Haberde kullanılan fotoğrafların haber ile uyumu sıklığı \%88 ile \%93 arasındadır. Haber siteleri haberi ile görselin uyumluluğu konusunda dikkat etmektedirler. Haber sitelerinde fotoğraf üzerinde sansasyonel kelime kullanımı \%2'nin altındadır. Bu sonuçlara göre örneklemdeki haber siteleri görsel ağırlıklı olmasının sebebi haber sitesi kullanıcısının görsel malzeme ile desteklenen haberi daha kolay ve hızlı algıladığından olabilir. Örneklemdeki haber siteleri bu nedenle haberi gerçek fotoğraf olmasa bile arşiv fotoğrafı ile desteklemektedir.

En çok ziyaret edilen haber sitelerinin ana sayfasında kadın figürü \%4'den \%32'ye kadar çıkmaktadır. Cinsellik ise bazı sitelerde hiç kullanılmazken bazı sitelerde \%12 ye kadar çıkmaktadır. Şiddet fotoğrafı kullanımı ise \%1'i bile bulmamaktadır.

En çok ziyaretçi alan haber siteleri ana sayfasında yer alan fotoğraflı haberlerin $\% 3,2$ 'den $\% 15,4$ 'e kadar fotoğraf galerisi bulunmaktadır. Video galeri ise $\% 5.1$ 'den $\% 15,8$ arasındadır. Türkiye'de yayınlanan haber siteleri multimedya özelliğinden yararlanmaktadır. 
Dingil, A.E. (2015). Türkçe haber siteleri tasarımları ve görsel kullanımı. International Journal of Social Sciences and Education Research, 1 (1), 250-261.

Çıkan sonuçlara göre magazin haberleri daha çok görsel ağılıklıdır. Magazin haberlerinin fotoğrafları ana sayfada daha çok yer almaktadır. Ardından siyaset haberleri ve spor haberleri gelmektedir. En çok tıklanan haber sitelerinin haber sitelerinde her türlü habere yer verilmektedir.

Örneklemdeki haber sitelerinde kayan resimler (slider) kullanmaktadır. Kayan resimlerde birçok haber türüne göre ( magazin, siyaset, spor, kültür - sanat, sağlık, polis - adliye vb.) haberler, foto galeri, video galeri bulunmaktadır.

Araştırmada en çok tıklanan haber sitelerinden en az bir olmak üzere 17 adete kadar slider kullanımı mevcuttur. İçerik analizi uyguladığımız 5 haber sitesinde haberturk.com 1 adet, milliyet.com 4 adet, haberler.com 6 adet, hurriyet.com 13 adet ve haber7.com 17 adet slider kullanmıştır. Bu kullanılan slider haber sayısı 3'den başlayıp 20'ye kadar çıkmaktadır. Bu sonuçlar gösteriyor ki en çok tıklanan haber sitelerinde slider kullanımı yaygındır.

Sonuç olarak günümüzde Türkçe haber siteleri Amerika ve Avrupa'daki örneklerine göre fotoğraf kullanımı yaygındır. Görsellik, haberi anlatmadaki önemi haber sitelerine de yansımaktadir.

\section{Kaynakça}

Çakır, H. (2007). Geleneksel gazetecilik karşısında internet gazeteciliği. Erciyes Üniversitesi Sosyal Bilimler Enstitüsü Dergisi, 22, 123 - 129.

Çevikel, T. (2004). Türkçe haber siteleri ve Türkiye'de internet gazeteciliğinin gelişimini sınırlayan faktörler. Galatasaray Üniversitesi İletişim Dergisi, 1, 147-165.

Devlet Planlama Teşkilatı. (2011). Bilgi Toplumu İstatistikleri. Ankara: Devlet Planlama Teşkilatı.

Güler, S. (2007). Yeni iletişim ortamlarının habercilik üzerine etkileri. Yayınlanmamış yüksek lisans tezi. İstanbul: Marmara Üniversitesi

Karaduman, M. (2005). Internet ve gazetecilik, yeni iletişim teknojileri ve medya içinde. İstanbul: IPS Vakfı Yayınlar1

MEB MEGEP, (2011). İnternet Haberciliği. Ankara: Milli Eğitim Bakanlığı.

Onursoy, S. (2001).Online haber yayımcllığında görsel tasarım boyutu: Haber sitesi örnekleri üzerine bir uygulama. Yayınlanmamış Doktora Tezi. Eskişehir: Anadolu Üniversitesi.

Onursoy, S., Kılıç, D., Er, F. (2010). Gazete Okuma Davranışı ve Okuma Yolu: Bir Göz İzleme Çalışmas1,.Marmara İletişim Dergisi, 16, 75-91.

Rigel, N. (2000). İleti Tasarımında Haber. İstanbul; Der Yayınları.

Tewksbury D. ve Althaus, S. L. (2000).Differences In Knowledge Acquisition among Readers of the Paper and Online Versions of a National Newspaper. Journalism and Mass Communication Quarterly, 457.

Uçak, O. (2012). Yazılı basında ve internet gazeteciliğinde kullanılan haber fotoğraflarının karş̧laştırılmas1. The Turkish Online Journal of Design, Art and Communication - TOJDAC. 2. (3). 73-80.

Yüksel, E. ve Gürcan H. İ. (2001). Habercinin El Rehberi, Soru ve Örneklerle Haber Toplama ve Yazma Kural ve Teknikleri, Eskişehir: Anadolu Üniversitesi Yayınları.

\section{İnternet Kaynakları}

www.alexa.com (Erişim tarihi: 11.02.2014)

www.hurriyet.com.tr (Erişim tarihi: 11.02.2014) 
Dingil, A.E. (2015). Website designs and visual applications of Turkish news sites. International Journal of Social Sciences and Education Research, 1 (1), 250-261.

Www.milliyet.com.tr (Erişim tarihi: 11.02.2014)

www.haber7.com.tr (Erişim tarihi: 11.02.2014)

www.haberturk.com.tr (Erişim tarihi: 11.02.2014)

www.haberler.com (Erişim tarihi: 11.02.2014)

www.sabah.com.tr (Erişim tarihi: 11.02.2014)

www.cnn.com (Erişim tarihi: 11.02.2014)

www.wordpress.com (Erişim tarihi: 11.02.2014)

www.foxnews.com (Erişim tarihi: 11.02.2014)

www.bbc.co.uk (Erişim tarihi: 11.02.2014)

www.dailymail.co.uk (Erişim tarihi: 11.02.2014)

www.theguardian.com (Erişim tarihi: 11.02.2014)

www.spigel.de (Erişim tarihi: 11.02.2014)

www.tonline.de (Erişim tarihi: 11.02.2014)

www.focus.de (Erişim tarihi: 11.02.2014)

www.tuik.gov.tr/PreHaberBultenleri.do?id=13569 (Erişim tarihi: 15.06.2014) 
Dingil, A.E. (2015). Türkçe haber siteleri tasarımları ve görsel kullanımı. International Journal of Social Sciences and Education Research, 1 (1), 250-261.

\section{Extended abstract in English}

The use visual design in the work Turkish news websites; the use visual design in the work Turkish news websites were examined. The development given from the past to present news websites, looking at the design of today's news websites in Europe, United States and Turkey today. While news is given on the home page, they also gave introduction on how to use applications. Today how news websites are designed are shown.

The place visual design of news websites occupied is the overall objective of this research. In this direction the image sizes on online news websites are investigated, the features that constitute the design was determined. Examining the home page of the websites questions were raised, Turkey has sought answers to these questions:

Sub-objectives of the research questions are as follows: What is the visual modalities and frequency of the news website? What is the actual visual use status in the news? The visual harmony of the news on the websites with the content of the news reports? The connection between the use of visual elements and design are applied in what way? How visual elements and the news topics are being distributed?

The research has been used as a method of content analysis. According to this method and data from alexa.com, which is the most clicked Turkish first five news websites www.hurriyet.com.tr, www.milliyet.com.tr, www.haber7.com, www.haberturk.com.tr and www.haberler.com all these websites' homepages were scanned. In this study, the visual usage and frequency, reality of the news (events occasions) and the ratio of image usage, the compliance of the visually with the news content on the website, how the visual elements are distributed according to the given topics of the news.

According to the data obtained by the content analysis of the survey, when it comes to all of the most-clicked news websites in Turkey floating images (slider) are available. The main page of the site is mostly dominated by the use of image news. According to this "online news website designs" the news found under the 1 st and 2nd floating images, conforms to the type of website design practices.

The Home pages of news websites are mainly visual. In the home pages of our scanned news websites there are over 100 news reports, where $70 \%$ to $97 \%$ of them are given in image forms. Some of these images are on the title and the spot. Titled-images over the spots rate has a frequency of between $14 \%$ and $50 \%$. The other news is located under or next to the Title and spot news. News websites uses more than $3 / 4$ archive images. Real image utilization rate is low.

The frequency of compliance with the notice of the images used in the news are between $88 \%$ and $93 \%$. News websites seem to care about the visual compatibility with the news reports. On the news websites, the use of the word sensational on image is less than $2 \%$. The reason for this is mainly based on the fact that news reports that are supported by visual material can be easily and quickly comprehended. Our sampled news websites therefore support us with archive images even if the actual image is not available.

Female figure on the homepages of the most visited news websites raise from $4 \%$. To $32 \%$. Gender however, while some websites are not using other websites usage raise up to $12 \%$. The use of violence images does not even reach $1 \%$. 
Dingil, A.E. (2015). Website designs and visual applications of Turkish news sites. International Journal of Social Sciences and Education Research, 1 (1), 250-261.

In most visited news websites, on the home pages' image news reports range from $3.2 \%$ to $15.4 \%$. Of the image gallery. The video gallery is between $5.1 \%$ and $15.8 \%$. News websites published in Turkey benefits from multimedia features.

According to the results magazine news reports are more visual. İmages of the magazine news are located more on the home page, then comes politics news and sports news. Most clicked news websites are included in it all kinds of news.

In our sample news websites, they all use floating images (slider). Most of the floating images are according to (magazines, politics, sports, culture - art, health and police - judiciary and so on.) News reports are in form of photo gallery and video gallery.

In our research, most clicked news websites have at least one up to 17 sliders available to use. From our content analysis, we used 5 news websites haberturk.com 1 piece, milliyet.com 4 pieces, 6 pieces from haberler.com hurriyet.co 13 pieces, haber7.com 17 pieces' sliders. In this slider, news can be numbered from 3 to 20 . These results show that the use of slider is common in most clicked news websites.

In conclusion, today there is now widespread use of images in Turkish news websites similar to America and Europe. Visually, Explains the importance of news which is reflected in news websites. 